\title{
Angin Koncang Tanjungbalai
}

Shohibul Anshor Siregar

Keramah-tamahan orang Tanjungbalai bisa dilihat dari banyak segi. Kalau ada orang jauh bertamu, niscaya tuan rumah akan berusaha menyajikan santapan korang robus (kerang rebus) dan sombom (lauk yang berbahan ikan). Adalah kebanggan bagi orang Tanjungbalai jika bisa menjamu tamu dengan kedua menu kebanggan itu. Sejatinya begitulah, kata Suhandi, seorang bernama mirip Jawa, asal Pasar Baru, Tanjungbalai.

Sekiranya tamu itu sudah makan, tuan rumah pun akan dengan halus tetap meminta agar hidangan dimakan: Makanlah kamu yo... sikit pun tak mangapo. Itu fakta-fakta keseharian (living realities), kata ahli komunikasi budaya Nirwansyahputra yang memiliki nama derivasi gabungan Sangskerta dan Persia, asal Bagan Asahan yang memiliki culture similarities (kemiripan budaya, atau mungkin malah menyatu) dengan kota kecil Tanjungbalai.

Sudah mendarah daging doktrin fal-yukrim dhayfah (memuliakan tetamu). Tanjungbalai yang adalah daerah pesisir terbuka (open coastal society) dengan karakter egaliter, tak pernah berharap bermusuhan dengan sesiapa pun (pajagojagohon) dan tak mewarisi watak xenophobia (khawatir dengan orang asing). Juga tak ada rasa rendah diri (minderwaardigheidscomplex, $\mathrm{mc}$ ) berhadapan dengan siapa pun. Kalau begitu mengapa orang-orang pada suatu malam penghujung bulan Juli 2016 bergerak tanpa komando membakar sejumlah Vihara dan Klenteng? Ini memang sebuah angin koncang (badai besar).

"Tanjungbalai kota korang. Korang dimakan asam sambalnyo. Takkan mungkin orang baporang, kalau tak ado asal panyobabnyo. Kamudi kapal payah dicari. Kalaupun dapat mahal haragonyo. Orang badame karono sahati, rapat kalbu nyawo taruhnyo." Ungkapan di atas dikemukakan Incek Elhayat, seorang jurnalis di Medan. Dipastikan bisa menjadi representasi kuat untuk pandangan semua orang mukim maupun perantau Tanjungbalai, baik tua mau pun muda, kelas menengah, bawah atau kelas atas. Tetapi mengapa amuk itu begitu spontan di kota yang bersemboyan "Balayar Satujuan Batambat Satangkahan" ini?

Kata Dja'far Siddik, seorang guru besar dari UIN asal Tanjungbalai, "biasalah guntur gemuruh di Lahore, petir menyambar di Karachi. Ini bukan sekedar gulai lomak, tapi berkaitan dengan sambal belacan asam kalubi. Banyak faktor. Guruh sudah beberapa kali berbunyi. Tapi orang menduga yang bakal turun hanya hujan biasa. Bila atap bocor, tampung saja dengan ember".

Angin koncang ini mestilah akumulasi kekecewaan menyejarah, kata Asrizal, seorang pensiunan PNS yang sepanjang karirnya bertugas di bagian informasi dan komunikasi. Kotanya kini sudah berubah menjadi "Tanjung Budha". Bukan lagi Tanjungbalai. Menurut sejarahnya, muara yang menjadi pertemuan dua sungai (sungai Asahan dan sungai Silau), itulah sebetulnya Tanjungbalai. Dahulu di tanjung itu berdiri sebuah bangunan (sebuah balai yang besar) yang menjelaskan identitas Melayu Tanjungbalai. Tetapi semasa pemerintahan Walikota Sutrisno Hadi, wilayah tanjung itu direklamasi. Balai yang dulunya berdiri tegak dan kokoh sebagai simbol budaya lokal, seakan 
digantikan sebuah patung raksasa Budha Amitabha seiring kontestasi penguasaan lahan.

Ada "penaklukan" sistematis dalam rivalitas asimetris. Betapa tak berdayanya Tanjungbalai. Guru saya, kata Incek Elhayat, pernah mewasiatkan. "Jangan sempat kami-kami yang berjuang dan dah tak ada akan berkata dari alam pusara: Roaitu baity ka baity, wa roaitu ahli laisa ka ahli [kutengok (kulihat) rumahku (negeriku) masih seperti yang dulu,tapi sayang penghuninya (penduduknya) bukan keluargaku yang dulu lagi]". Akar masalahnya (the root of the problem) mulai terlihat. Angin koncang akhir Juli 2016 bukan kerusuhan biasa. Karena itu, mengedepankan pendekatan pidana dengan tuduhan provakator, penjarah dan apa pun konstruk hukumnya, akan mengakibatkan keabadian masalah. Tambahkan saja sejumlah orang lagi pada daftar tersangka, hingga banyak warga yang keluar dari rumah saat kerusuhan, diadili dan kemudian dipenjarakan. Namun akar masalah akan tetap terbungkus. Itu pasti mengundang angin koncang yang lebih besar.

Dja'far Siddik melanjutkan penjelasannya: "Semua mungkin masih ingat berdirinya patung Budha tinggi menjulang, yang sama sekali tak bersentuhan dengan budaya setempat, sempat menimbulkan guruh. Begitu pula guruh-guruh lainnya. Akhirnya Walikota Tanjungbalai memprakarsai aksi bersama penandatanganan sebuah kesepakatan (3 Agustus 2010). Itu sebagai kelanjutan rakor Muspida Plus dengan Komisi A DPRD Kota Tanjungbalai dan Gerakan Islam Bersatu (28 Juli 2010), yang menjadi lanjutan dari rapat dengan pemuka agama (30 Juli 2010), dan rapat Walikota dengan Pengurus Yayasan Vihara Tri Ratna (2 Agustus 2010) yang menyatakan memindahkan posisi patung Budha ke tempat lain yang terhormat.

Kesepakatan 3 Agustus 2010 itu disusul dengan surat Walikota kepada Ketua Yayasan Vihara Tri Ratna (30 September 2010, No. 100/18349/T-an/2010). Surat itu mengingatkan tindak lanjut kesepakatan bersama, sekaligus mempertanyakan mengapa Patung raksasa Budha belum diturunkan. Walikota juga mengingatkan agar pengurus Yayasan Vihara Tri Ratna sesegera mungkin menurunkan Patung Budha Amitabha sebagaimana disepakati dalam dalam surat kesepakatan bersama". Tapi sayang kesepakatan itu tidak digubris. Mengapa? Sebegitu rendahkah kewibawaan Walikota di mata pemilik patung Amitabha? Agaknya itulah yang terjadi. "Apa lu belani ama kita olang, begitulah ecek-eceknya”, kata Dja'far Siddik menyindir. Angin koncang ternyata selalu diundang.

Sisi lain mestilah ditilik untuk memahami angin koncang akhir Juli 2016 Tanjungbalai. Mengapa Melayu kehilanganlead? Itu karena mereka tak mampu menggenggam ekonomi sendiri. Mereka kalah dalam perebutan sumberdaya di bawah pemerintahan yang umumnya sama dengan di bagian-bagian lain Indonesia, yakni memilih peran sebagai penonton belaka, sambil mengumpul upeti. Akhirnya semua sumberdaya didominasi toke-toke yang sekaligus memenangi persaingan keras menjadi imam peradaban. Melayu yang akhirnya hidup dalam himpitan kesulitan ekonomi dalam involusi yang parah berkepanjangan, tersingkir meski tetap tak merubah salero bagulai loma" (biar bagubuk condong asal bagulai lomak). 
Angin koncang di kota Tanjungbalai juga pernah terjadi lebih keras. Tanggal 27 Mei 1988, jelas Nasakti On dalam sebuah tulisan yang tayangkan pada sebuah media online, Tanjungbalai rusuh. Awalnya tiga anak penyemir sepatu ditendang oleh seorang warga turunan etnis Tionghoa pemilik sebuah toko perabot di Jalan Sisingamangaraja. Penendangan itu dianggapnya sebagai cara pantas untuk mengusir dari toko tempatnya berusaha. Cepat sekali berita itu tersebar menimbulkan situasi memanas. Ketika itu seorang tokoh pemuda pemilik pesantren Modern Al-Falah, $\mathrm{H}$. Buyung, mengambil inisiatif membawa ketiga korban ke DPRD kota Tanjungbalai. Di sana segera digelar sidang terbatas untuk menengahi agar tidak menjurus SARA, dan massa yang ingin mengetahui duduk kejadian tak terbendung. Seirama dengan pembicaraan dalam sidang terbatas, segera pula massa yang berada di sekitar gedung DPRD tanpa dikomando terbagi dua. Ada yang tetap tinggal (di sekitar gedung) dan sebagian mendatangi toko perabot milik warga turunan Tionghoa tadi.

Di toko perabot massa menemukan pengawalan ketat sejumlah orang sipil dengan seragam organisanya. Organisasi ini bertindak cepat, sebelum sasaran amuk massa meluas, seluruh toko milik warga turunan etnis Tionghoa dipastikan sudah mendapat pengawalan ketat. Merasa sangat confidance, seorang tokoh pemuda keturunan etnis Tionghoa yang sangat terkenal di kota itu dengan pengawalan ketat dari sejumlah tukang pukul malah melakukan patroli di jalanan dengan mobil jip Williss terbuka, masing-masing dilengkapi senjata api.

Tindakan patroli malah menimbulkan kemarahan lebih besar. Massa melempari rumah-rumah milik warga turunan etnis Tionghoa. Nyali orang-orang sipil berseragam organisasi yang melakukan pengawalan akhirnya menjadi ciut, mereka memilih menyelamatkan diri dan menanggalkan baju seragam. Solidaritas mereka tergugah melihat keadaan. Situasi kota Tanjungbalai pun tidak terkendali, amuk massa sudah berada di luar kendali pihak keamanan. Kelompok-kelompok binaan tokoh pemuda sangat berpengaruh keturunan etnis Tionghoa itu pun bubar, masing masing memilih menyelamatkan diri. Situasi baru mulai aman ketika pasukan TNI dari Pematangsiantar hadir dengan mengawali tindakan pemblokiran seluruh akses masuk ke kota Tanjungbalai.

Angin koncang Tanjungbalai bukan hal baru. Malah adalah fungsi tetap dari sebuah kompleksitas sosial, politik dan budaya yang hadir pada saat yang memuncak. Jelas pula bukan khas Tanjungbalai. Di Indonesia kini hampir semua suku, agama, etnik dan golongan serta daerah, bagaikan ilalang kering yang sangat mudah terbakar atau dibakar, tegas Musni Umar, sosiolog dari UIN Jakarta. Sangat sulit diterima oleh akal sehat seorang perempuan keturunan etnis Tionghoa datang ke masjid memrotes kumandang azan yang dianggapnya mengganggu, kemudian masyarakat marah dan membakar puluhan Vihara dan Klenteng. Ini tidak mungkin terjadi jika tidak ada prolog yang membuat masyarakat tidak suka, benci, anti dan marah terhadap warga keturunan etnis Tionghoa.

Dalam setiap konflik yang bernuansa SARA, pemerintah dan aparat tidak pernah berusaha mencari akar masalah yang menjadi penyebab, tegas Musni Umar. Di tingkat domestik dan lokal, kata Musni Umar, ada masalah serius yang dirasakan sebagai ketidak-adilan. 
Pertama, kesenjangan sosial ekonomi. Sudah menjadi realitas bahwa ekonomi dikuasai warga turunan etnis Tionghoa yang makin lama semakin kaya karena aparat dan kepala daerah bekerja sama dengan mereka. Setiap pemilihan kepala daerah (pilkada), jelas Musni Umar, mereka menjadi cukong calon-calon yang bertarung. Siapapun pemenang otomatis merasa berhutang budi.

Kedua, tumbuh arogansi terhadap pribumi. Ini penyakit orang kaya yang dilindungi oleh aparat. Mereka tidak lagi sensitif menyaring kata dan kalimat, sehingga masyarakat memendam kebencian dan kemarahan.

Ketiga, persepsi masyarakat menjadi sangat negatif karena setiap terjadi masalah, aparat selalu memihak.

Keempat, kebijakan dan perlakuan yang mengistimewakan yang kaya, yang kebetulan adalah warga turunan etnis Tionghoa, telah memancing perasaan tidak adil yang sewaktu-waktu diledakkan jika ada masalah sekecil apapun.

Kelima, faktor global turut memengaruhi masyarakat berperilaku temperamental, cepat marah dan emosi.

Angin koncang Tanjungbalai adalah sebuah pesan serius untuk Indonesia. Saya setuju solusi Musni Umar mengedepankan penyelesaian kesenjangan sosial ekonomi. Affirmative action terhadap mereka yang lemah terutama kaum pribumi sebagaimana dicontohkan Malaysia melalui New Economic Policy (NEP) patut ditiru. Hal-hal remeh-temeh lainnya yang biasa dikedepankan oleh para pembijaksana, bisalah itu menyusul, bahkan kelak bisa dipidatokan berulang-ulang sambil blusuan kian kemari menjelang pemilu atau pilpres untuk memberi bahan pencitraan melalui pemberitaan media mainstream.

Tetapi Indonesia harus diselamatkan dengan cinta berkeadilan. Bukankah untuk masalah seperti ini Negara harus hadir menurut Nawacita?

Shohibul Anshor Siregar. Naskah ini pertamakali diterbitkan oleh harian Waspada, Senin 8 Agustus 2016, hlm B7 